\section{Comparing intravitreal triamcinolone acetonide and bevacizumab injections for the treatment of diabetic macular oedema: a randomized double- blind study}

\author{
David Leonardo Cruvinel Isaac, Murilo Batista Abud, Kariza \\ Aiko Frantz, Alan Ricardo Rassi and Marcos Avila
}

Department of Ophthalmology, Federal University of Goias, Goiania, Brazil

\begin{abstract}
.
Purpose: To compare the effect of a single intravitreal injection of triamcinolone acetonide and bevacizumab in reducing macular thickness, which was measured by optical coherence tomography (OCT) in patients with diabetic macular oedema (DMO).

Methods: The patients received a single intravitreal injection of $1.25 \mathrm{mg}$ bevacizumab in one randomly selected eye and $4.0 \mathrm{mg}$ triamcinolone acetonide in the contralateral eye. Central foveal thickness measurement (CFT) with OCT was taken at the initial visit and at the 4-week, 12-week and 24-week visits.

Results: Eleven patients ( 22 eyes) were enrolled and statistically analysed. CFT reduced in the eyes treated with triamcinolone and those treated with bevacizumab in weeks 4 and $12(\mathrm{p}<0.05)$. At the 24-week follow-up, no significant difference was noted, relative to the initial visit. Comparing the two groups treated with different drugs, a statistically significant difference in CFT in weeks 4 and 12 was noted, with a more significant reduction in triamcinolone-treated eyes $(p<0.05)$. Regarding visual acuity (VA), patients treated with triamcinolone had improvement in VA at 4-week $(p=0.02)$ and 12 -week follow-up $(p=0.01)$, while the group treated with bevacizumab had VA improvement at 4 -week follow-up $(p=0.02)$. Among the eyes treated with triamcinolone, intraocular pressure (IOP) measurement of more than $21 \mathrm{mmHg}$ was found in three eyes $(27.3 \%)$.

Conclusions: Intravitreal triamcinolone proved to be more efficient in reducing DMO, providing longer lasting visual improvement, relative to bevacizumab. Eyes treated with triamcinolone had the highest percentage increase in IOP. Further studies are needed to corroborate these findings.
\end{abstract}

Key words: bevacizumab - complications from diabetes - diabetic retinopathy - macular oedema/ therapy - triamcinolone acetonide/administration \& dosage - triamcinolone acetonide/therapeutic use - visual acuity

Acta Ophthalmol. 2012: 90: 56-60

(c) 2009 The Authors

Journal compilation (c) 2009 Acta Ophthalmol

doi: $10.1111 /$ j.1755-3768.2009.01817.x

\section{Introduction}

Macular oedema is the main cause of visual loss in diabetic patients, affecting around $30 \%$ of the patients who have had the disease for more than 20 years (Klein et al. 1984). The Early Treatment Diabetic Retinopathy Study (ETDRS) investigated the role and the uniformization of photocoagulation for the treatment of diabetic macular oedema (DMO). In this study, focal or grid macular photocoagulation showed a $50 \%$ reduction in the risk of developing moderate visual loss in 3 years. However, in $24 \%$ of the treated eyes, visual acuity (VA) was maintained or became worse (Early Treatment Diabetic Retinopathy Study 1985).

Many studies have demonstrated VA and macular thickness improvement after intravitreal injections in diabetic patients with macular oedema refractory to treatment with photocoagulation. These studies involve the use of intravitreal triamcinolone acetonide (Martidis et al. 2002; Jonas et al. 2003a; Massin et al. 2004; Gillies et al. 2004, 2006; Larsson et al. 2009), and more recently the use of intravitreal bevacizumab (Haritoglou et al. 2006; Arevalo et al. 2007; Scott et al. 2007; Fang et al. 2008; Lam et al. 2009). The DRCRnet study determined, however, that at the end 
of 3 years, the use of triamcinolone acetonide alone did not result in benefits greater than that obtained by macular photocoagulation alone (Beck et al. 2009). In clinical practice, the use of focal photocoagulation associated with triamcinolone or bevacizumab is relatively frequent, and studies on these associations have demonstrated the benefits of therapy combined with photocoagulation, as a sole treatment option (Kang et al. 2006; Shimura et al. 2007; Saraiva et al. 2008; Maia et al. 2009).

There are questions over which drug, associated or not with focal photocoagulation, would be more efficient in the reduction of the oedema. Recently, two studies compared intravitreal bevacizumab with intravitreal triamcinolone acetonide for the treatment of DMO. In both studies, triamcinolone was more efficient (Paccola et al. 2008; Shimura et al. 2008).

The goal of this study is to compare the effect of a single intravitreal injection of triamcinolone acetonide and bevacizumab in reducing central macular thickness measured by optical coherence tomography (OCT) in patients with macular oedema secondary to diabetic retinopathy.

\section{Patients and Methods}

\section{Patient eligibility}

This is a prospective, double-blind, interventionist, comparative and randomized study, performed in the Reference Center in Ophthalmology of the Federal University of Goias, Brazil. Patients who fit the criteria were included after having read and signed an informed consent form. Inclusion criteria were as follows: DMO with or without previous photocoagulation with central macular thickness measured by OCT of more than $300 \mu \mathrm{m}$ in both eyes, glycosylated haemoglobin of up to $1 \%$ above the reference value of the method and blood pressure lower than $160 \times 90 \mathrm{mmHg}$ measured at initial visit. Exclusion criteria were as follows: retinal disease other than diabetic retinopathy, unilateral pseudophakia, cataract surgery $<3$ months before the enrolment, intravitreal or periocular injection of triamcinolone or bevacizumab, previous vitrectomy, retinal photocoagulation $<3$ months before the enrolment, active prolifera- tive diabetic retinopathy, macular ischaemia diagnosed by fluorescein angiography, use of corticosteroids orally or injected $<30$ days before this trial, patients with glaucoma or patients with cataract that could preclude fundus evaluation and diagnostic tests.

The medical history of all the patients considered for inclusion in this study was taken, and they all underwent a comprehensive ocular examination which included measurement of best corrected visual acuity (BCVA), anterior segment biomicroscopy, applanation tonometry and slitlamp biomicroscopy of the macula. A TRC-50IA fundus camera (Topcon, Tokyo, Japan) and the software IMAGENET 2000 were used to perform fluorescein angiography and to detect macular ischaemia or retinal neovascularization. OCT was used to measure central foveal thickness (CFT) - a $1000-\mu \mathrm{m}$ central field obtained by six scans of the 'Fast Macular Thickness' software (OCT-3 Stratus; Zeiss Systems, San Leandro, CA, USA).

\section{Treatment and follow-up}

The drawing to randomize the patients to the drug which would be injected in one of the eyes was conducted by someone not participating in the study. Each patient received one intravitreal injection of $1.25 \mathrm{mg}(0.05 \mathrm{ml})$ bevacizumab (Avastin; Genetech, Inc, Redwood city, CA, USA) in one eye and $4.0 \mathrm{mg}(0.1 \mathrm{ml})$ triamcinolone acetonide (Theracort $40 \mathrm{mg}$, Igepharma S.A., Sao Paulo, Brazil) in the contralateral eye. All the injections were given by the same investigator, in a sterile environment, after topical anaesthesia with proximetacaine at 5\% (Anestalcon; Alcon, Sao Paulo, Brazil) and instillation of povidone-iodine at $5 \%$. The drug was injected through pars plana by a standardized tunnel technique at $3.5 \mathrm{~mm}$ from the corneal limbus with a 30 -gauge needle (Rodrigues et al. 2007). Immediately after the injection, one of these two tests was performed: VA measured with the finger counting method or indirect ophthalmoscopic evaluation of central retinal artery perfusion. After the procedures, the patients were instructed to use gatifloxacin antibiotic eye drops at $0.03 \%$ every $6 \mathrm{hr}$ for 1 week (Zymar; Allergan, Guarulhos, Brazil).
All the patients were evaluated at the 1st and 7 th postoperative days by the treatment investigator. Only this investigator knew what treatment had been used in each eye. At the 4-, 12- and 24week follow-up visits, the ophthalmological examinations were performed by the follow-up investigator. Both the OCT and the fluorescein angiography were performed by certified examiners. If the intraocular pressure (IOP) was higher than $21 \mathrm{mmHg}$ in any of the visits, the patient would be treated with antiglaucoma eye drops.

\section{Statistical analysis}

Descriptive statistics was used to present the data as means and standard deviation. Kolmogorov-Smirnov test was performed. CFT and IOP showed normal distribution while VA was determined as a nonparametric variable. Student's $t$-test was used to calculate statistical differences between CFT values and IOP during the pre- and posttreatment visits, for the samples paired for the follow-up analysis of eyes receiving the same type of drug. The same $t$-test was used for independent samples, for different treatment groups. The Wilcoxon and the Mann-Whitney tests were used to analyse VA test values, and a $\mathrm{p}$ value of $<0.05$ was considered statistically significant. The two-tailed $\mathrm{p}$ analysis was used for all the tests.

\section{Results}

Thirteen patients were included in the study, and two were excluded from the sample. One patient did not attend the 4- and 12-week visits, and the other because OCT foveal images were displaced from actual foveal centre in the initial visit. The remaining 22 eyes of 11 patients completed the 6 months proposed for follow-up and were studied.

Among the 11 patients studied, six were men $(54.55 \%)$. All the patients had type 2 diabetes mellitus, and the mean age was $64.6 \pm 9.75$ years. One patient presented bilateral pseudophakia $(9.1 \%)$, and the remaining patients presented lenses bilaterally $(90.9 \%)$.

\section{Foveal thickness}

In the initial visit, the CFT in the patients who would be treated with triamcinolone was $453 \pm 88 \mu \mathrm{m}$, while in 
the group of patients receiving bevacizumab, CFT was $528 \pm 105 \mu \mathrm{m}$. No significant difference was found between them $(\mathrm{p}=0.087)$.

Four weeks after the triamcinolone injection, CFT decreased to $266 \pm$ $53 \mu \mathrm{m}(\mathrm{p}<0.001)$. In 12 weeks, it measured $296 \pm 96 \mu \mathrm{m} \quad(\mathrm{p}=0.003)$ and in 24 weeks, $406 \pm 125 \mu \mathrm{m}(\mathrm{p}=$ $0.17)$. At the 24 -week visit, no statistically significant difference was noted, relative to the initial visit.

In the group of eyes injected with bevacizumab, a statistical difference was noted in the CFT between the initial and the 4-week visit when CFT was $389 \pm 84 \mu \mathrm{m} \quad(\mathrm{p}=0.002)$ and between the initial and the 12-week visit when CFT was $399 \pm 120 \mu \mathrm{m}$ $(p=0.02)$. Compared to the initial visit, a CFT of $486 \pm 150 \mu \mathrm{m}$ $(\mathrm{p}=0.43)$ measured at the 24-week follow-up visit showed no statistically significant difference.
Between the two groups of eyes treated with different drugs, there was a significant difference in the CFT in week $4(\mathrm{p}<0.001)$ and $12(\mathrm{p}=$ 0.038 ), but there was no statistical difference between the groups at the 24week visit $(p=0.18)$. CFT values are shown in Figs 1 and 2.

\section{Visual acuity and intraocular pressure}

In patients treated with triamcinolone, VA improved from $0.72 \pm 0.23$ LogMar to $0.50 \pm 0.26(\mathrm{p}=0.02)$ at the 4-week visit and to $0.49 \pm 0.31(\mathrm{p}=$ $0.01)$ at the 12 -week visit. At the 24week visit, VA was $0.59 \pm 0.41(\mathrm{p}=$ 0.18 ), a difference which was not statistically significant, relative to the initial visit.

In those patients treated with bevacizumab, VA improved from $0.72 \pm$ 0.37 LogMar to $0.55 \pm 0.27 \quad(\mathrm{p}=$ $0.02)$ at the 4-week visit. At the 12-

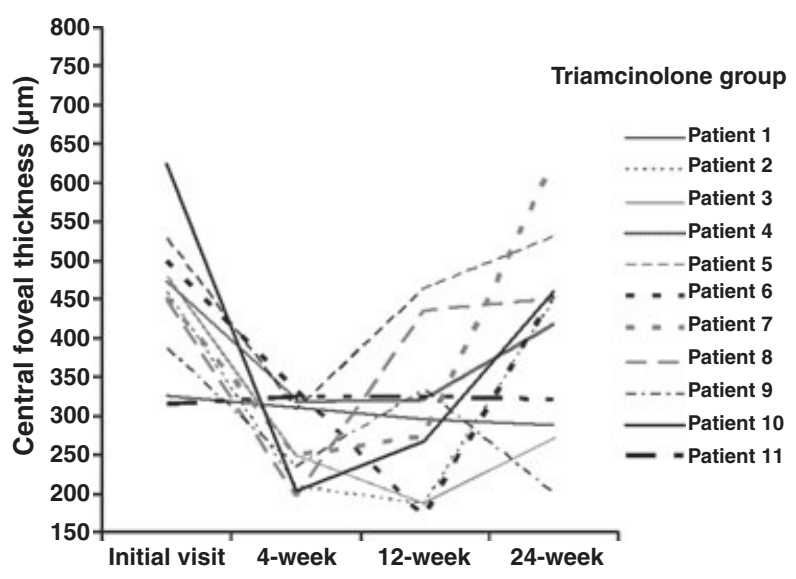

Fig. 1. Diagram showing the individual course of central foveal thickness after intravitreal injection of triamcinolone acetonide for all eyes included in the study.

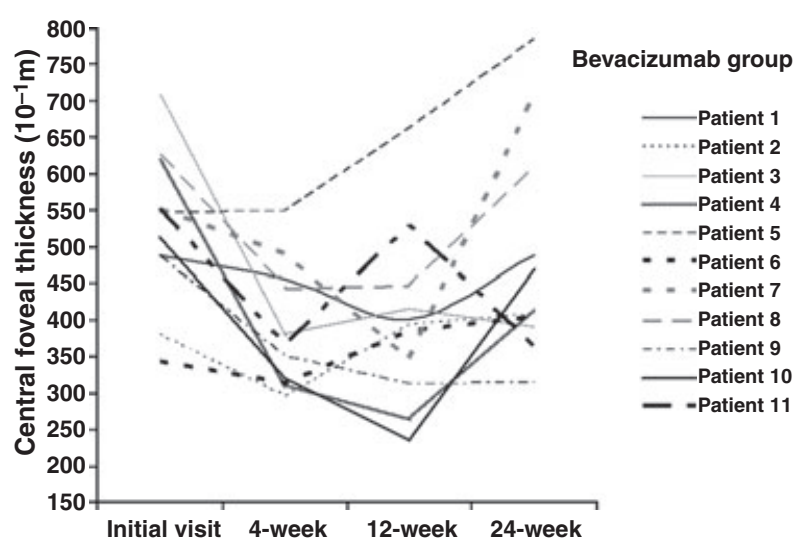

Fig. 2. Diagram showing the individual course of central foveal thickness after intravitreal injection of bevacizumab for all eyes included in the study.

week visit, VA was $0.63 \pm 0.30(\mathrm{p}=$ 0.18 ) and at the 24-week visit, VA was $0.72 \pm 0.36 \quad(p=0.95)$. There was no difference between the 12- and 24-week visits, relative to the initial visit.

Among the treated groups, no statistical difference was noted in any of the visits, with regard to VA: initial visit $(\mathrm{p}=0.79)$, 4-week visit $(\mathrm{p}=$ $0.57), 12$-week visit $(\mathrm{p}=0.27)$ and $24-$ week visit $(\mathrm{p}=0.45)$. The VA values measured at each visit, using the LogMar scale, are found in Figs 3 and 4.

Regarding IOP in the group of eyes treated with triamcinolone, no statistical difference was found between the initial visit and the 4 -week $(p=0.08)$ and the 24-week visits $(\mathrm{p}=0.25)$. However, a statistically significant difference regarding week $12(\mathrm{p}=0.01)$ was determined. Among the eyes treated with triamcinolone, IOP in three eyes $(27.3 \%)$ increased to more than $21 \mathrm{mmHg}$, and for this reason, they were treated with antiglaucoma drugs. In the group of eyes treated with bevacizumab, no difference in IOP was found between the initial visit and the 4 -week visit $(\mathrm{p}=0.10)$, the 12 -week visit $(\mathrm{p}=0.14)$ and the 24 -week visit $(p=0.11)$. In the group of eyes treated with bevacizumab, all the IOP measurements were below $21 \mathrm{mmHg}$.

Among the groups of eyes treated with triamcinolone and bevacizumab, no difference was found between the IOP value determined in the initial visit $(\mathrm{p}=0.49)$, the 4 -week $(\mathrm{p}=0.08)$, the 12-week $(\mathrm{p}=0.08)$ and the 24week visits $(\mathrm{p}=0.45)$.

\section{Discussion}

The doses used in this study corresponded to those frequently used in the clinical practice and in previous studies (1.25 mg bevacizumab and $4.0 \mathrm{mg}$ triamcinolone acetonide) (Martidis et al. 2002; Massin et al. 2004; Haritoglou et al. 2006; Gillies et al. 2006; Scott et al. 2007; Arevalo et al. 2007; Paccola et al. 2008; Shimura et al. 2008). The mechanisms involved in establishing macular oedema involve inflammatory factors and increased levels of vascular endothelial growth factor (Funatsu et al. 2008; Patel et al. 2008). For this reason, at least theoretically, it would be possible to attribute 


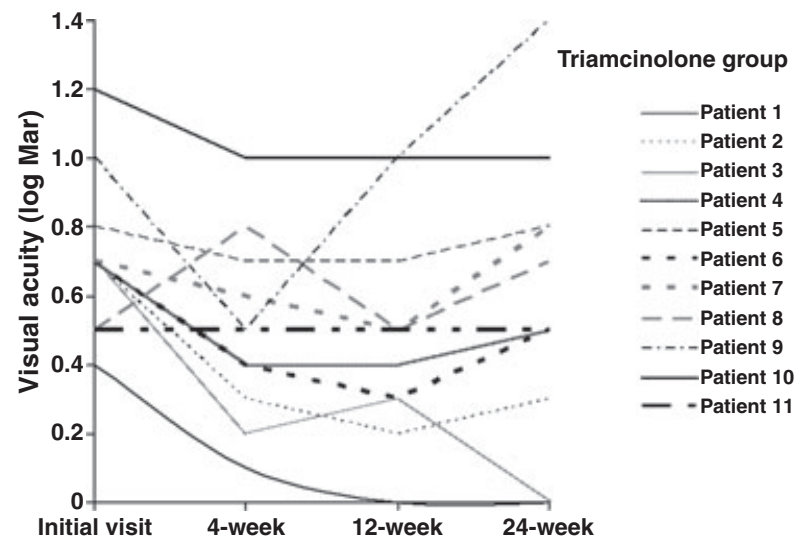

Fig. 3. Diagram showing the individual course of visual acuity after intravitreal injection of triamcinolone acetonide for all eyes included in the study.

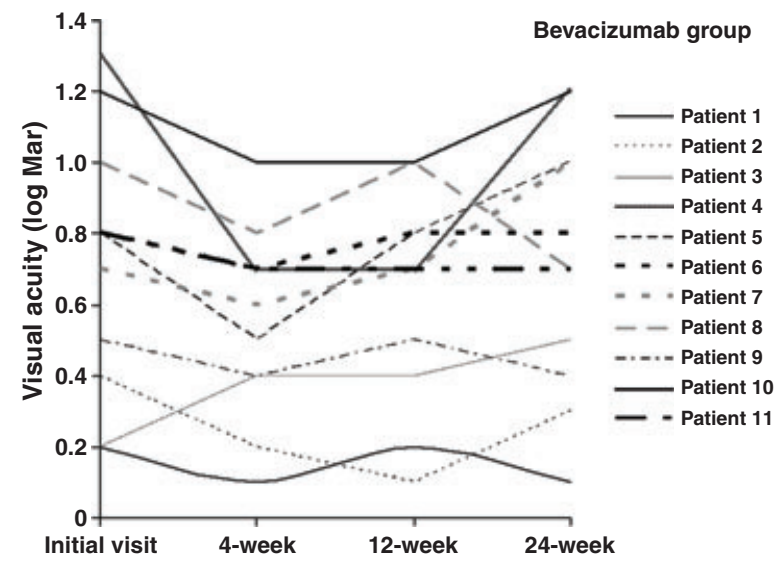

Fig. 4. Diagram showing the individual course of visual acuity after intravitreal injection of bevacizumab for all eyes included in the study.

a beneficial effect when corticosteroids and antiangiogenic agents were used to treat diabetic oedema.

In this study, a reduction in CFT was observed in both groups. Both the single intravitreal injection of triamcinolone and the single injection of bevacizumab caused a significant reduction in CFT at the 4-week and 12-week follow-up, relative to the initial visit. However, when we compare the effects of both drugs, triamcinolone showed a greater reduction power, regarding the CFT, and this effect was more pronounced at weeks 4 and 12. At the 24-week follow-up visit, an increase in the CFT was noted, and there was no significant difference among the groups studied. The data are similar to those obtained by the investigations conducted by Paccola et al. (2008) and Shimura et al. (2008), suggesting that triamcinolone is better at reducing DMO than bevacizumab.
Regarding oedema reduction in terms of percentage, in the 4-week visit, the investigators noted a $41.26 \%$ reduction in the CFT in eyes treated with triamcinolone, compared to $26.41 \%$ in the bevacizumab-treated eyes. Shimura et al. (2008) found, in a 1-week follow-up, a $34.4 \%$ reduction with triamcinolone and a $24.2 \%$ reduction with bevacizumab, while the results of the Pan-American Collaborative Retina Study Group showed a $25.6 \%$ reduction in the oedema at week 4 (Arevalo et al. 2007), which is similar to data from this study. In the Paccola et al. (2008) and the Shimura et al. (2008) studies, this more significant reduction in the oedema in eyes treated with triamcinolone persisted until the 24-week visit, in spite of the trend towards an increase in the oedema in both groups. This study showed a worsening of the oedema at the 24-week visit in both groups of eyes included in the study, and these findings were similar to those found by Massin et al. (2004), who compared a single triamcinolone intravitreal injection to the untreated contralateral eye in patients with DMO. These observations suggest the limited effect of both drugs in terms of reducing macular oedema, with a trend towards an increase in foveal thickness in periods longer than 6 months. Successive injections are needed to maintain the reduction effect of the oedema for long periods of time (Gillies et al. 2004; Kook et al. 2008; Beck et al. 2009; Lam et al. 2009).

A frequent adverse effect described for the intraocular use of triamcinolone is corticosteroid glaucoma. Several studies have demonstrated an increase in IOP to more than $21 \mathrm{mmHg}$ in treated eyes followed for more than 1 month (Jonas et al. 2003b, 2004; Smithen et al. 2004; Gillies et al. 2004), with the incidence ranging from 36 to $52 \%$ of the patients. In this study, the IOP was higher than $21 \mathrm{mmHg}$ in three $(27.3 \%)$ of the 11 eyes treated with triamcinolone, in one of the visits. Of the three affected eyes, two had increased IOP in the 12-week visit and one in the 24 -week visit. A statistically significant difference was found between values obtained in the initial visit and those obtained in the 12week visit. Absence of statistical significance in week 24 could be explained by a possible reduction in mean IOP, caused by the reduction in the triamcinolone effect, or even because of the normalization of the IOP of the two patients who had shown an elevated IOP in the 12-week visit. They were then treated with antiglaucoma drugs. The stability of IOP values in patients who received bevacizumab makes it a potential adjuvant drug for the treatment of DMO, especially in patients with glaucoma or with increased IOP, resulting from the use of corticosteroids.

Regarding VA, both medications resulted in visual improvement. The benefit of triamcinolone, however, was more prolonged and statistically significant at weeks 4 and 12 , while for bevacizumab, an improvement was only noted in week 4 , with a visual worsening in subsequent visits. 
Some limitations can be identified in the present study. Besides the small number of eyes studied, there was no separation between patients who had already received previous macular photocoagulation from treatment naïve patients. Glycosylated haemoglobin and blood pressure levels were only measured at the initial visit. During the follow-up period, uncontrolled blood pressure or glycemia levels might have been undiagnosed. In this series, 20 eyes $(90.9 \%)$ were phakic, and all these eyes had at least initial cataract. The presence of cataract may have contributed to the absence of significant difference in VA between groups treated with different drugs.

In this study, the investigators compared single intravitreal injections of triamcinolone and bevacizumab in paired eyes, for the treatment of DMO. The study demonstrated that triamcinolone acetonide was more efficient in reducing oedema and provided a longer lasting visual improvement, relative to bevacizumab. During the follow-up period, however, eyes treated with triamcinolone had the highest percentage increase in IOP. New studies, with a greater number of patients, are needed to corroborate these findings.

\section{References}

Arevalo JF, Fromow-Guerra J, Quiroz-Mercado $\mathrm{H}$ et al; Pan-American Collaborative Retina Study Group (2007): Primary intravitreal bevacizumab (Avastin) for diabetic macular edema: results from the PanAmerican Collaborative Retina Study Group at 6-month follow-up. Ophthalmology 114: 743-750.

Beck RW, Edwards AR, Aiello LP et al; The Diabetic Retinopathy Clinical Research Network (DRCR.net) (2009): Three-year follow-up of a randomized trial comparing focal/grid photocoagulation and intravitreal triamcinolone for diabetic macular edema. Arch Ophthalmol 127: 245-251.

Early Treatment Diabetic Retinopathy Study Research Group (1985): Photocoagulation for diabetic macular edema. Early Treatment Diabetic Retinopathy Study report number 1. Arch Ophthalmol 103: 17961808.

Fang X, Sakaguchi H, Gomi F et al. (2008): Efficacy and safety of one intravitreal injection of bevacizumab in diabetic macular oedema. Acta Ophthalmol 86: 800-805.

Funatsu H, Yamashita H, Ikeda T, Mimura T, Eguchi S \& Hori S (2008): Vitreous levels of interleukin-6 and vascular endothelial growth factor are related to diabetic macular edema. Ophthalmology 110: 1690-1696. Gillies MC, Simpson JM, Billson FA et al. (2004): Safety of an intravitreal injection of triamcinolone: results from a randomized clinical trial. Arch Ophthalmol 122: 336 340.

Gillies MC, Sutter FK, Simpson JM, Larsson J, Ali H \& Zhu M (2006): Intravitreal triamcinolone for refractory diabetic macular edema: two-year results of a doublemasked, placebo-controlled, randomized clinical trial. Ophthalmology 113: 15331538.

Haritoglou C, Kook D, Neubauer A et al. (2006): Intravitreal bevacizumab (Avastin) therapy for persistent diffuse diabetic macular edema. Retina 26: 999-1005.

Jonas JB, Kreissing I, Sofker A \& Degenring RF (2003a): Intravitreal injection of triamcinolone for diffuse diabetic macular edema. Arch Ophthalmol 121: 57-61.

Jonas JB, Kreissing I \& Degenring $\mathrm{R}$ (2003b): Intraocular pressure after intravitreal injection of triamcinolone acetonide. Br J Ophthalmol 87: 24-27.

Jonas JB, Degenring R, Kreissig I \& Akkoyun I (2004): Safety of intravitreal high-dose reinjections of triamcinolone acetonide. Am J Ophthalmol 138: 1054-1055.

Kang SW, Sa HS, Cho HY \& Kim JI (2006): Macular grid photocoagulation after intravitreal triamcinolone acetonide for diffuse diabetic macular edema. Arch Ophthalmol 124: $653-658$

Klein R, Klein BE, Moss SE, Davis MD \& DeMets DL (1984): The Wisconsin Epidemiologic Study of Diabetic Retinopathy. Diabetic macular edema. Ophthalmology 91: 1464-1474.

Kook D, Wolf A, Kreutzer T, Neubauer A, Strauss R, Ulbig M, Kampik A \& Haritoglou C (2008): Long-term effect of intravitreal bevacizumab (Avastin) in patients with chronic diffuse diabetic macular edema. Retina 28: 1053-1060.

Lam DS, Lai TY, Lee VY, Chan CK, Liu DT, Mohamed S \& Li CL (2009): Efficacy of 1.25 MG versus 2.5 MG intravitreal bevacizumab for diabetic macular edema: six-month results of a randomized controlled trial. Retina 29: 292-299.

Larsson J, Kifley A, Zhu M, Wang JJ, Mitchell P, Sutter FK \& Gillies MC (2009): Rapid reduction of hard exudates in eyes with diabetic retinopathy after intravitreal triamcinolone: data from a randomized, placebo-controlled, clinical trial. Acta Ophthalmol 87: 275-280.

Maia OO Jr, Takahashi BS, Costa RA, Scott IU \& Takahashi WY (2009): Combined laser and intravitreal triamcinolone for proliferative diabetic retinopathy and macular edema: one-year results of a randomized clinical trial. Am J Ophthalmol 147: 291-297.

Martidis A, Duker JS, Greenberg PB, Rogers AH, Puliafito CA, Reichel E \& Baumal C (2002): Intravitreal triamcinolone for refractory diabetic macular edema. Ophthalmology 109: 920-927.

Massin P, Audren F, Haouchine B, Erginay A, Bergmann JF, Benosman R, Caulin C \& Gaudric A (2004): Intravitreal Triamcinolone Acetonide for Diabetic Diffuse Macular Edema Preliminary Results of a Prospective Controlled Trial. Ophthalmology 111: 218-225.

Paccola L, Costa RA, Folgosa MS, Barbosa JC, Scott IU \& Jorge R (2008): Intravitreal triamcinolone versus bevacizumab for treatment of refractory diabetic macular edema. Br J Ophthalmol 92: 76-80.

Patel JI, Saleh GM, Hykin PG, Gregor ZJ \& Cree IA (2008): Concentration of haemodynamic and inflammatory related cytokines in diabetic retinopathy. Eye 22: 223-228.

Rodrigues EB, Meyer CH, Grumann A Jr, Shiroma H, Aguni JS \& Farah ME (2007): Tunneled scleral incision to prevent vitreal reflux after intravitreal injection. Am $\mathrm{J}$ Ophthalmol 143: 1035-1037.

Saraiva FP, Queiroz MS, Costa PG, Gasparin F \& Nakashima Y (2008): Use of intravitreal triamcinolone and laser photocoagulation for the treatment of diffuse diabetic macular edema. Arq Bras Oftalmol 71: 493-498.

Scott IU, Edwards AR, Beck RW et al; for the Diabetic Retinopathy Clinical Research Network (2007): A phase II randomized clinical trial of intravitreal bevacizumab for diabetic macular edema. Ophthalmology 114: $1860-1867$.

Shimura M, Nakazawa T, Yasuda K, Shiono $T$ \& Nishida K (2007): Pretreatment of posterior subtenon injection of triamcinolone acetonide has beneficial effects for grid pattern photocoagulation against diffuse diabetic macular edema. Br J Ophthalmol 91: 449-454.

Shimura M, Nakazawa T, Yasuda K, Shiono $\mathrm{T}$, Iida $\mathrm{T}$, Sakamoto $\mathrm{T}$ \& Nishida $\mathrm{K}$ (2008): Comparative therapy evaluation of intravitreal bevacizumab and triamcinolone acetonide on persistent diffuse diabetic macular edema. Am J Ophthalmol 145: 854-861.

Smithen LM, Ober MD, Maranan L \& Spaide RF (2004): Intravitreal triamcinolone acetonide and intraocular pressure. Am J Ophthalmol 138: 740-743.

Received on July 11th, 2009.

Accepted on October 22nd, 2009.

\section{Correspondence:}

David Leonardo Cruvinel Isaac

Rua C-259 No. 441 Ap.701 Setor Nova Suica Goiania

Goias

Brazil 74280-220

Tel: + 556299685480

Fax: + 556232525500

Email: cruvinelisaac@hotmail.com 